\title{
Attentional capture modulates perceptual sensitivity
}

\author{
JAN THEEUWES \\ Vrije Universiteit, Amsterdam, The Netherlands \\ ARTHUR F. KRAMER \\ Beckman Institute and University of Illinois at Urbana-Champaign, Urbana, Illinois \\ and \\ ALAN KINGSTONE \\ University of British Columbia, Vancouver, British Columbia, Canada
}

\begin{abstract}
The present study was designed to determine the spatial distribution of attention in displays in which an irrelevant color singleton was present. The results show that the presence of an irrelevant color singleton modulates target detectability $\left(d^{\prime}\right)$. The presence of an irrelevant singleton reduces the gain for input at the target location, particularly when the irrelevant color singleton was close to the target singleton. In line with earlier claims, it is argued that the capture of attention by the irrelevant singleton causes a reduced sensory input at the target location.
\end{abstract}

When watching a football game, a particular event (e.g., the sudden change of a billboard) may grab your attention. Did this event grab your attention because you were set for it (i.e., keeping track of things that change), or did it grab your attention automatically even though your top-down goal was to watch the game? This example illustrates one of the most debated questions in the study of visual attention: Can visual stimuli capture attention independently of our goals, beliefs, or intentions? (For recent reviews see, e.g., Ruz \& Lupiáñez, 2002; Theeuwes \& Godijn, 2001). Goal-directed or top-down control of selection refers to the ability to select those areas, objects, features, and events needed for our current tasks. Stimulus-driven or bottom-up selection refers to the capacity of certain stimulus attributes to attract our attention irrespective of our goals and beliefs. When objects or events receive priority independently of the observer's goals and beliefs, we have an example of attentional capture (Yantis \& Egeth, 1999).

In recent years, there have been several demonstrations of attentional capture. For example, Yantis and Jonides (1984; see also Jonides \& Yantis, 1988; Theeuwes, 1990) showed that abrupt onsets and not static feature singletons have the ability to capture attention. In their experiments, there was always one feature singleton present, yet the feature singleton was task irrelevant because its location was uncorrelated with the position of the target.

We thank Brad Gibson, Chip Folk, and Tram Neill for their helpful comments on an earlier draft of this paper. Correspondence concerning this article should be addressed to J. Theeuwes, Department of Cognitive Psychology, Vrije Universiteit, Van der Boechorststraat 1, 1081 BT Amsterdam, The Netherlands (e-mail: j.theeuwes@psy.vu.nl).
In other words, participants had no incentive to attend deliberately to the feature singleton. Using this paradigm, Jonides and Yantis (1988; see also Yantis \& Egeth, 1999) concluded that only abrupt onsets capture attention exogenously (e.g., automatically).

Theeuwes (1991, 1992, 1996; Theeuwes, Atchley, \& Kramer, 2000) also investigated attentional capture by feature singletons. Theeuwes $(1991,1992,1994)$ used a visual search task (known as the additional singleton task) in which two salient singletons were presented simultaneously. The logic underlying the additional singleton task is simple: Participants perform a visual search task in which one item in the display is the target singleton whereas another singleton is completely unrelated and irrelevant to the task. This condition is compared to one in which the irrelevant singleton is not present. For example, Theeuwes (1992) presented participants with circular displays consisting of identically colored circles and one diamond. Line segments of different orientations appeared in the circles and diamonds, and the participants had to determine the orientation of the line segment appearing in the target shape. The target shape for which the participants searched was a singleton, because it was the only diamond present in the display. In the distractor condition, an irrelevant color singleton was also present in the display. Time to find the shape singleton increased when an irrelevant color singleton was present (i.e., when one of the circles was red). The increase in search time in conditions in which an irrelevant singleton was present was explained in terms of attentional capture. Theeuwes $(1991,1992,1994)$ argued that irrespective of the attentional set of the observer, spatial attention was captured by the salient distractor singleton 
before it could be redirected to the target singleton (see Theeuwes et al., 2000, for evidence in support of this assertion). The initial bottom-up shift of attention to a salient singleton is thought to be the result of relatively inflexible, "hardwired" mechanisms.

There is a continuing controversy with respect to whether attentional capture in Theeuwes's $(1991,1992,1994)$ additional singleton task is indeed completely bottom up (see, e.g., Folk \& Remington, 1998; Folk, Remington, \& Johnston, 1992). For example, Bacon and Egeth (1994) suggested that attentional capture was found in Theeuwes's visual search task because participants adopted a singleton detection strategy to find the target. When participants engage in this strategy, they direct attention to the location having the largest feature contrast (which was the distractor singleton). However, when participants choose a feature detection strategy there is no attentional capture by the irrelevant singleton. Even though this notion is viable, in a recent study Theeuwes (2004) showed that the idea of differential search strategies may be questionable and that the absence of capture may not be the result of differential top-down search strategy, but simply of reduced salience of bottom-up signals.

Notwithstanding the ongoing dispute concerning whether feature singletons capture attention in a purely bottom-up fashion (for some recent studies, see Abrams \& Christ, 2003; Boot, Brockmole, \& Simons, 2004; Franconeri \& Simons, 2003; Horstmann, 2002; Theeuwes, 2004), it is generally agreed that the presence of an irrelevant salient singleton slows search for a target singleton.

The present study was designed to both (1) provide converging evidence that irrelevant singletons influence perceptual sensitivity or detectability of target processing and (2) determine the spatial distribution of attention in displays in which an irrelevant singleton is present. Instead of measuring response latency, we employed methods derived from signal detection theory (SDT). Unlike reaction times (RTs), signal detection measures allow for the separation of perceptual and decision-level effects of attention. To map out the spatial distribution of visual attention, we employed a method similar to that used by
Handy, Jha, and Mangun (1999, see also Handy, Kingstone, \& Mangun, 1996; Hawkins et al., 1990). Participants were required to make a two-choice forced decision regarding the orientation of a small target bar, which was consistently located in the shape singleton (a gray diamond among gray circles). On some trials, an irrelevant color singleton (a red circle) was present.

Given previous research and theorizing, we expect that the presence of a singleton distractor will influence the detectability of the predefined target, as reflected in measures of perceptual sensitivity. Furthermore, we predict that sensitivity will also be modulated as a function of the distance between the singleton target and the distractor, suggesting that disruption of processing by the task-irrelevant singleton is the result of spatial attention.

\section{METHOD}

\section{Participants}

Fifteen participants took part in the experiment. All had selfreported normal or corrected-to-normal vision and reported having no color vision defects.

\section{Stimuli}

The display was similar to that of Theeuwes (1992). Nine display elements were spaced at equal intervals around the fixation point on an imaginary circle (5.8 radius). The display consisted of eight gray outlines of circles $\left(1.94^{\circ}\right.$ in diameter; $\left.4.6 \mathrm{~cd} / \mathrm{m}^{2}\right)$ and one diamond $\left(1.9^{\circ}\right.$ per side), which constituted the target shape singleton. In the distractor condition, one of the gray circles was replaced by a red circle $\left(8.5 \mathrm{~cd} / \mathrm{m}^{2}\right)$. The target-distractor singleton distance was systematically varied: The number of elements between the target and the distractor was $0,1,2$, or 3 , representing a separation of $4.0^{\circ}, 7.4^{\circ}, 10.4^{\circ}$, or $11.4^{\circ}$ (Euclidian distance, center to center), respectively. A small gray target bar $\left(0.73^{\circ}\right)$ was consistently placed inside the target shape singleton. The mask consisted of a set of randomly oriented filled gray line segments $\left(4.6 \mathrm{~cd} / \mathrm{m}^{2}\right)$ at various orientations. Figure 1 gives an example of the displays.

\section{Procedure}

The procedure was similar to that of Handy et al. (1999). A fixation cross was presented for $1,000 \mathrm{msec}$, followed by the display for $116 \mathrm{msec}$, which was then immediately masked for another $116 \mathrm{msec}$. The participants were required to direct their attention to the shape singleton and to make a discrimination judgment of the

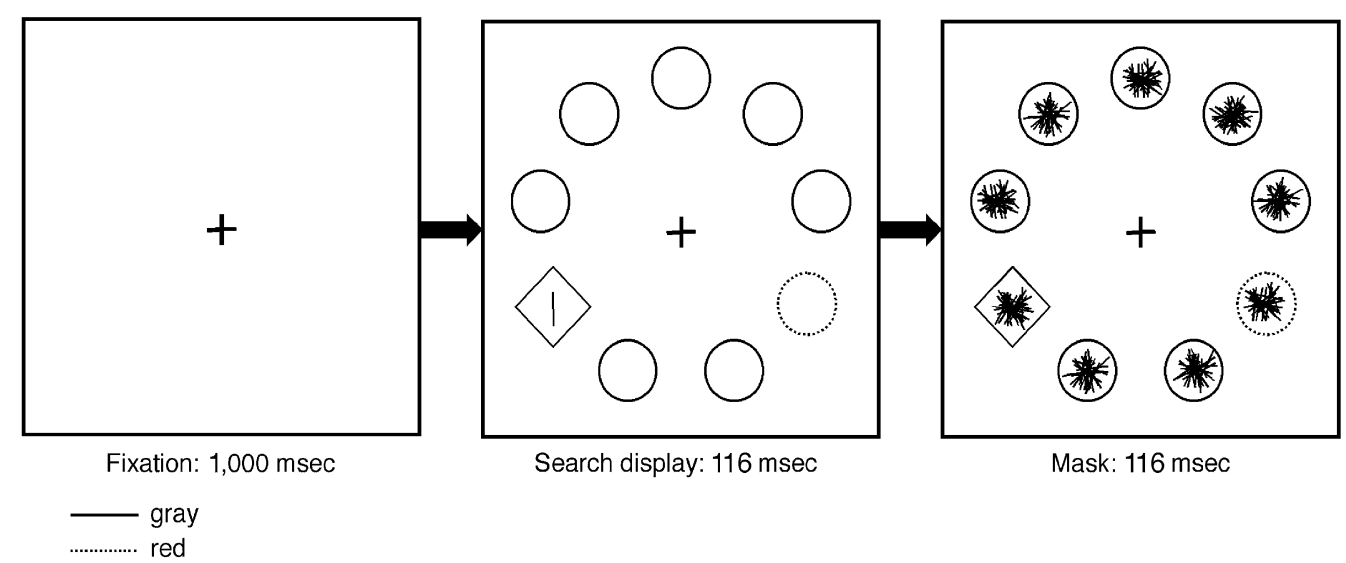

Figure 1: A graphical illustration of the sequence and timing of stimulus events presented on each trial. 
target bar's orientation (i.e., vertical or horizontal) inside the shape singleton. The participants were required to respond only to the designated target orientation (i.e., on "go" trials only), which was counterbalanced across participants. A hit was defined as a response on trials in which the designated target orientation was present, and a false alarm was defined as a response on trials in which the designated target orientation was absent. Accuracy was stressed. The participants received feedback about their hit and false alarm rates every 72 trials.

In order to minimize the possibility of floor or ceiling effects in accuracy, target line length was adjusted on line to ensure that performance remained near $75 \%$ correct. Every 10 trials, the overall performance (hits and false alarms) was calculated. If overall accuracy dropped below $65 \%$, line length was increased. If performance was better than $85 \%$, line length was reduced. Since no-distractor and distractor trials were randomized in blocks, the adjustment procedure was used for both conditions.

\section{Design}

In total, the participants performed 864 experimental trials run on 2 separate days. Before the start of the experiment, the participants performed 144 practice trials. During practice, the search display was presented longer than it was during the experimental trials (for $166 \mathrm{msec}$ instead of $116 \mathrm{msec}$ ). There was an equal number of distractor and no-distractor trials. For the distractor condition, a distractor could be presented near $\left(0\left[4.0^{\circ}\right]\right.$ or $1\left[7.4^{\circ}\right]$ element between target and distractor) or far $\left(2\left[10.4^{\circ}\right]\right.$ or $3\left[11.4^{\circ}\right]$ elements between target and distractor). There was an equal number of targetdistractor distances. All conditions were randomized within each block of trials.

\section{RESULTS}

The $d^{\prime}$ and $A^{\prime}$ measures ${ }^{1}$ were calculated for each participant. The data of 1 participant were removed because of a $d^{\prime}$ of less than 0.70 (which was half of the mean $d^{\prime}$ of the other participants). Table 1 presents the mean $d^{\prime}$ 's, hit rates, false alarm rates, and $A^{\prime}$ 's for the no-distractor and distractor conditions. When no distractor was present, both $d^{\prime}$ and $A^{\prime}$ were significantly higher than they were when a distractor was present [for $d^{\prime}, F(1,13)=$ 6.67, $M S_{\mathrm{e}}=0.024, p<.05$; for $A^{\prime}, F(1,13)=7.00$, $\left.M S_{\mathrm{e}}=0.00038, p<.05\right]$.

In an additional analysis, we calculated the $d^{\prime}$ as a function of target-distractor distance (near vs. far). Planned comparisons showed that, relative to the no-distractor condition $\left(d^{\prime}=1.52\right)$, a near distractor significantly reduced $d^{\prime}\left[d^{\prime}=1.30 ; F(1,13)=9.77, M S_{\mathrm{e}}=0.034, p<\right.$ $.001]$. A far distractor had no effect on $d^{\prime}\left(d^{\prime}=1.46 \mathrm{vs}\right.$. $\left.d^{\prime}=1.52 ; F<1\right)$. The difference in $d^{\prime}$ between a close distractor and a far distractor was reliable $\left[d^{\prime}=1.30 \mathrm{vs}\right.$. $d^{\prime}=1.46 ; F\left[(1,13)=4.70, M S_{\mathrm{e}}=0.037, p<.05\right]$.

Table 1

Mean $d^{\prime}$, Hit Rate, False Alarm Rate, and $A^{\prime}$ for the No-Distractor and Distractor Conditions

\begin{tabular}{|c|c|c|c|c|c|c|c|c|}
\hline & \multicolumn{2}{|c|}{$d^{\prime}$} & \multicolumn{2}{|c|}{$\begin{array}{l}\text { Hit } \\
\text { Rate }\end{array}$} & \multicolumn{2}{|c|}{$\begin{array}{c}\text { False Alarm } \\
\text { Rate }\end{array}$} & \multicolumn{2}{|c|}{$A^{\prime}$} \\
\hline & $M$ & $S D$ & $M$ & $S D$ & $M$ & $S D$ & $M$ & $S D$ \\
\hline No distractor & 1.52 & 0.277 & .797 & 0.077 & .260 & 0.097 & 0.855 & 0.037 \\
\hline Distractor & 1.37 & 0.302 & .788 & 0.067 & .295 & 0.078 & 0.824 & 0.044 \\
\hline
\end{tabular}

\section{DISCUSSION}

The present results are clear. When searching for a shape singleton, the presence of a color singleton modulates target detectability. Spatial cuing studies showed that increased spatial attention can enhance gains for inputs (e.g., Handy et al., 1999; Hawkins et al., 1990). The present findings indicate that the presence of an irrelevant singleton reduces the gain for input at the target location. In line with earlier claims (e.g., Theeuwes, 1991, 1992, 1994), it is assumed that the presence of an irrelevant singleton reduces the sensory gain at the target location because the irrelevant singleton captures spatial attention. It is this capture of attention by the irrelevant singleton that results in reduced attention at the target location, leading to a reduced target detectability.

The present finding confirms those of earlier studies in which RT was used as the principal dependent measure (e.g., Theeuwes, 1992). It has been argued that RT and signal detection measures index different aspects of attention-related processing (see, e.g., Handy et al., 1996; Hawkins et al., 1990). It is generally agreed that $d^{\prime}$ reflects earlier perceptual processing such as the sensory encoding of a stimulus (see, e.g., Handy et al., 1996), whereas RT can reflect both earlier perceptual and later responserelated operations. The present observation that the effect on $d^{\prime}$ is similar to that on RT confirms earlier claims that RT data obtained with an additional singleton paradigm (Theeuwes, 1992) represents additional perceptual processing and not operations occurring after an item has been selected for processing (such as the speed by which attention can be disengaged from a distractor location; see Theeuwes \& Godijn, 2001, for a discussion).

The finding that target detectability $\left(d^{\prime}\right)$ is affected only by distractors close to the target and not by distractors presented farther away is in line with findings reported by Mounts (2000a, 2000b) and Caputo and Guerra (1998; see also Cave \& Zimmerman, 1997; Cepeda, Cave, Bichot, \& Kim, 1998; Theeuwes \& Godijn, 2001). Mounts (2000a) argued that a target-distractor distance effect should be considered as additional evidence that the distractor singleton captured attention. It is argued that the consequence of selecting an object is the inhibited processing of neighboring objects. Mounts (2000a) explains the mechanism by which selection occurs in these tasks in terms of inhibition to prevent ambiguities in perceptual coding (see, e.g., Luck, Girelli, McDermott, \& Ford, 1997) or in terms of resources - that is, the salient item pulls more resources away from the closer than from the more distant elements (see, e.g., Bahcall \& Kowler, 1999).

Even though the target-distractor separation effect may be explained in terms of inhibitory surround processing, it may also be consistent with an attentional capture account. Note, however, that, according to an attentional capture account that assumes that time to reorient attention to the target increases with target-distractor distance, the distance effect should increase with increasing separation between target and distractor. In the present ex- 
periment, we found the opposite pattern, which seems to be incompatible with an attentional capture account. Nevertheless, there is little evidence that the time to shift attention depends on the distance over which attention must be shifted. In fact, Kwak, Dagenbach, and Egeth (1991) provided a compelling demonstration that attention shifts are time invariant to the distance traveled. Thus, when time-invariant shifts are assumed, there should be no distance effect: Attention is captured by the singleton distractor and shifts in a time-invariant way to the target.

That a singleton close to the target causes a larger effect on $d^{\prime}$, however, is in accord with the recent demonstration that signal salience plays a crucial role in attentional capture (Theeuwes, 2004). It is possible that the salience of the singleton target depends on the extent to which this singleton target stands out from its environment. An element surrounded by a homogeneous group of contrasting elements will be more salient than an element that is surrounded by a less homogeneous local environment. Therefore, it is possible that the buildup of activation signaling the singleton target is slower when a color singleton is nearby than when the color singleton is on the opposite side of the visual field. According to this view, the closer the singleton distractor is to the singleton target, the less salient the singleton target becomes and the longer it takes to reorient attention to the singleton target after it has been captured by the color singleton. This mechanism is related to the weight linkage process described by Duncan \& Humphreys (1989), which refers to the ease with which nontarget elements can be rejected. Obviously, if the activation signaling the singleton target depends on the extent to which the singleton target is unique in its local surroundings, then the separation effect represents simply the strength of activations and not inhibitory processing.

\section{REFERENCES}

Abrams, R. A., \& Christ, S. E. (2003). Motion onset captures attention. Psychological Science, 14, 427-432.

BACON, W. F., \& EGETH, H. E. (1994). Overriding stimulus-driven attention capture. Perception \& Psychophysics, 55, 485-496.

BahCall, D. O., \& Kowler, E. (1999). Attentional interference at small spatial separations. Vision Research, 39, 71-86.

Boot, W. R., Brockmole, J. R., \& SimONs, D. J. (2004). Modulation of attentional capture in a dual task situation: Why capture is not stimulus driven. Manuscript submitted for publication.

Caputo, G., \& Guerra, S. (1998). Attentional selection by distractor suppression. Vision Research, 38, 669-689.

Cave, K. R., \& Zimmerman, J. M. (1997). Flexibility in spatial attention before and after practice. Psychological Science, 8, 399-403.

Cepeda, N. J., Cave, K. R., Вichot, N. P., \& Kim, M.-S. (1998). Spatial selection via feature-driven inhibition of distractor locations. Perception \& Psychophysics, 60, 727-746.

Duncan, J., \& Humphreys, G. W. (1989). Visual search and stimulus similarity. Psychological Review, 96, 433-458.

Folk, C. L., \& RemingTON, R. W. (1998). Selectivity in distraction by irrelevant featural singletons: Evidence for two forms of attentional capture. Journal of Experimental Psychology: Human Perception \& Performance, 24, 847-858.

FoLK, C. L., REMINGTON, R. W., \& Johnston, J. C. (1992). Involuntary covert orienting is contingent on attentional control settings. Journal of Experimental Psychology: Human Perception \& Performance, $\underline{\mathbf{1 8}}$, 1030-1044.

FrANCONERI, S. L., \& Simons, D. J. (2003). Moving and looming stimuli capture attention. Perception \& Psychophysics, 65, 999-1010.
Handy, T. C., Jha, A. P., \& Mangun, G. R. (1999). Promoting novelty in vision: Inhibition of return modulates perceptual-level processing. Psychological Science, 10, 157-161.

Handy, T. C., Kingstone, A., \& Mangun, G. R. (1996). Spatial distribution of visual attention: Perceptual sensitivity and response latency. Perception \& Psychophysics, 58, 613-627.

Hawkins, H. L., Hillyard, S. A., Luck, S. J., Mouloua, M., DownING, C. J., \& WoodwARD, D. P. (1990). Visual attention modulates signal detectability. Journal of Experimental Psychology: Human Perception \& Performance, 16, 802-811.

HoRSTMANN, G. (2002). Evidence for attentional capture by a surprising color singleton in visual search. Psychological Science, 13, 499-505.

JonidEs, J., \& YANTIS, S. (1988). Uniqueness of abrupt visual onset in capturing attention. Perception \& Psychophysics, 43, 346-354

KWAK, H.-W., DagenBACH, D., \& EgETH, H. (1991). Further evidence for a time-independent shift of the focus of attention. Perception \& Psychophysics, 49, 473-480.

LuCK, S. J., GirelLi, M., McDermott, M. T., \& Ford, M. A. (1997). Bridging the gap between monkey neurophysiology and human perception: An ambiguity resolution theory of visual selective attention. Cognitive Psychology, 33, 64-87.

MaCmillan, N. A., \& CREelman, C. D. (1996). Triangles in ROC space: History and theory of "nonparametric" measures of sensitivity and response bias. Psychonomic Bulletin \& Review, 3, 164-170.

MounTs, J. R. W. (2000a). Attentional capture by abrupt onsets and feature singletons produces inhibitory surrounds. Perception \& Psychophysics, 62, 1485-1493.

MounTs, J.R. W. (2000b). Evidence for suppressive mechanisms in attentional selection: Feature singletons produce inhibitory surrounds. Perception \& Psychophysics, 62, 969-983.

RUZ, M., \& LuPIÁÑEZ, J. (2002). Attentional capture and exogenous orienting: Upon their automaticity and sensitivity to endogenous control. Psicológica, 23, 283-309.

Theeuwes, J. (1990). Perceptual selectivity is task dependent: Evidence from selective search. Acta Psychologica, 74, 81-99.

Theeuwes, J. (1991). Cross-dimensional perceptual selectivity. Perception \& Psychophysics, 50, 184-193.

Theeuwes, J. (1992). Perceptual selectivity for color and form. Perception \& Psychophysics, 51, 599-606.

TheEUwes, J. (1994). Stimulus-driven capture and attentional set: Selective search for color and visual abrupt onsets. Journal of Experimental Psychology: Human Perception \& Performance, 20, 799-806.

THEEUWES, J. (1996). Perceptual selectivity for color and form: On the nature of the interference effect. In A. F. Kramer, M. G. H. Coles, \& G. D. Logan (Eds.), Converging operations in the study of visual attention (pp. 297-314). Washington, DC: American Psychological Association.

TheEuwes, J. (2004). Top-down search strategies cannot override attentional capture. Psychonomic Bulletin \& Review, 11, 65-70.

Theeuwes, J., Atchley, P., \& Kramer, A. F. (2000). On the time course of top-down and bottom-up control of visual attention. In S. Monsell \& J. Driver (Eds.), Attention and performance XVIII (pp. 105-124). Cambridge, MA: MIT Press.

Theeuwes, J., \& GodiJn, R. (2001). Attention and oculomotor capture. In C. L. Folk \& B. S. Gibson (Eds.), Attraction, distraction, and action: Multiple perspectives on attentional capture (pp. 121-150). Amsterdam: Elsevier.

YANTIS, S., \& EGETH, H. E. (1999). On the distinction between visual salience and stimulus-driven attentional capture. Journal of Experimental Psychology: Human Perception \& Performance, 25, 661-676.

YANTIS, S., \& JONIDES, J. (1984). Abrupt visual onsets and selective attention: Evidence from selective search. Journal of Experimental Psychology: Human Perception \& Performance, 10, 601-621.

\section{NOTE}

1. Unlike $d^{\prime}, A^{\prime}$ is a signal detection measure that does not assume normal distributions of signal and noise (see Macmillan \& Creelman, 1996). 